\title{
A lack of clinically apparent vision loss among vigabatrin-treated patients with infantile spasms: The UCLA experience
}

Madeline D. Schwarz ${ }^{\mathrm{a}}$, Menglu Li ${ }^{\mathrm{b}}$, Jackie Tsao ${ }^{c}$, Raymond Zhou ${ }^{c}$, Yvonne W. Wu $^{\mathrm{a}, \mathrm{e}}$, Raman Sankar ${ }^{\mathrm{c}, \mathrm{d}}$, Joyce Y. Wu ${ }^{c}$, Shaun A. Hussain ${ }^{c}$

${ }^{a}$ School of Medicine and ${ }^{\mathrm{e}}$ Department of Neurology, University of California, San Francisco, San Francisco, CA, USA; 'bchool of Medicine and Health Sciences, George Washington University, Washington DC, USA; 'Division of Pediatric Neurology and ${ }^{\mathrm{d}}$ Department of Neurology, Mattel Children's Hospital and David Geffen School of Medicine at UCLA, Los Angeles, CA, USA.

Abstract Word Count: 411

Manuscript Word Count: 2459

References: 27

Figures: 3

Key Words: West Syndrome, epileptic spasms, peripheral, retina, vision loss

Corresponding Author:

Shaun Hussain, MD

UCLA Pediatric Neurology

10833 Le Conte Ave, Room 22-22474

Los Angeles, CA, USA 90095-1752

Phone: +1 (310) 825-6196

Fax: +1 (310) 825-5834

Email: shussain@mednet.ucla.edu 


\begin{abstract}
Background: Vigabatrin (VGB) is one of two FDA-approved medications for treatment of infantile spasms. Despite demonstrated efficacy, its use has been curtailed by reports indicating a substantial risk of VGB-associated visual field loss (VAVFL). As these reports have conflicted with our clinical observations in routine practice, we systematically reviewed the experiences of patients treated with VGB at UCLA to estimate the prevalence of clinically apparent VAVFL.

Methods: Patients with video-EEG confirmed infantile spasms evaluated at our center between February, 2007 and February, 2014 were retrospectively identified. Among patients with VGB exposure, we documented relevant clinical factors and determined the duration of therapy, peak dosage, and cumulative dosage. Based on review of serial neurologic and ophthalmologic reports, and aided by electroretinography (ERG) assessments when available, we ascertained whether each patient had evidence of clinically-apparent vision impairment (i.e., recognized by a neurologist or ophthalmologist during any follow-up visit), and whether or not the vision loss was attributed to VGB exposure (i.e. evidence of bilateral, symmetric, peripheral visual field loss) either by the treating physician, or on retrospective review by the study team

Results: During the study period, 257 patients with video-EEG confirmed infantile spasms were identified. One-hundred and forty-three (56\%) patients received VGB. Although visual loss of any cause was common among patients with (31\%) and without (32\%) VGB exposure, there were no cases in which visual field defects were plausibly linked to VGB. We estimate the risk of clinically significant VAVFL does not exceed 3.2\% (95\% Cl upper bound). Vision loss was never characterized as exclusively peripheral, and was always better explained by other causes (e.g. hemianopsia following hemispherectomy, cortical vision impairment after hypoxic ischemic encephalopathy, etc.). Precise quantitative exposure data were available for 104 (73\%) VGB-treated patients, among whom median duration of treatment was 8.6 (IQR 3.7 - 16.2) months, median peak dosage was 141.5 (IQR $104.8-166.0$ ) $\mathrm{mg} / \mathrm{kg} / \mathrm{day}$, and median cumulative dosage was 314 (IQR 140.8 - 645.7) grams.

Conclusions: We found that the risk of clinically apparent vision loss is quite low among young children treated for infantile spasms. Our estimate of risk contrasts with prior studies and likely reflects our ascertainment of vision loss without the aid of perimetry or serial ERG, the short treatment duration, and the relatively young age of our patients. In the treatment of infantile spasms, risk-benefit assessment should consider both the low prevalence of ERG-identified VAVFL among patients with brief $(<6-9 \mathrm{mo})$ exposure and the very low prevalence of clinically apparent VAVFL in this population.
\end{abstract}




\section{Introduction}

Infantile spasms is a frequently devastating form of epilepsy which usually presents in the first year of life.[1] It is characterized by clusters of brief seizures termed spasms and severe electroencephalographic abnormalities including hypsarrhythmia.[2] A lack of prompt and successful treatment often results in adverse neurodevelopmental outcomes.[3] Given this urgency and the developmental costs of unsuccessful treatment, practitioners routinely employ high-risk treatments including corticosteroids,[4] adrenocorticotropic hormone,[5] and vigabatrin (VGB).[6] Despite established efficacy, $[7,8]$ the use of VGB has been curtailed by reports of retinopathy manifesting with permanent bilateral concentric peripheral visual field defects in adults[9] and children,[10] termed vigabatrin-associated visual field loss (VAVFL). To a lesser extent, the use of VGB has also been deterred by the threat of reversible and usually subclinical T2 signal changes seen with brain MRI.[11-14] VGB is appropriately restricted to those patients for whom the potential benefit outweighs risk.

There are conflicting estimates of the risk and severity of VAVFL. In a large-scale meta-analysis, the prevalence of VAVFL among patients treated for partial-onset epilepsy was higher in adults (52\%) than in older children (34\%).[15] In contrast, two small case series describing children with VGB exposure in infancy each reported a risk of VAVFL under 7\%, as determined by Goldman kinetic perimetry performed years later. $[16,17]$ This discrepancy led to speculation that VAVFL may occur in an age-dependent fashion or may be reversible.[18,19] However, these studies were limited by potential selection bias and by uncertain validity of kinetic perimetry when performed on young children.[20] A subsequent study of 35 children with VGB exposure in infancy found a duration-dependent risk of VAVFL ranging from 9\% among children treated for less than 12 months to $63 \%$ among children treated for more than 24 months, with VAVFL assessed by perimetry at the age of at least 9 years.[21] Further complicating the interpretation of these studies is a lack of consensus as to the minimum age or developmental status required of children undergoing kinetic perimetry. False positive results frequently occur with a lack of robust cooperation on the basis of youth and intellectual status.[10,16,22]

The challenge of visual field testing in young children has prompted many clinicians to employ electroretinography (ERG) to evaluate the retina in a rigorous fashion in infants undergoing VGB treatment.[23] In a recent and large-scale cohort study of children treated with VGB for infantile spasms, a significant reduction in 30-Hz ERG flicker response amplitude from baseline was observed among 30 of 146 (21\%) children. [24] ERG-defined retinopathy was least frequent (5.6\%) in patients who received VGB for less than 6 months. Whether ERG measures are an adequate marker of VAVFL remains controversial. In their description of 39 children who underwent both ERG and perimetry, Moskowitz and colleagues reported a lack of association between $30-\mathrm{Hz}$ flicker response amplitude and actual visual field defects on perimetry.[25] No study has adequately quantified or described how VAVFL impacts patient functioning or quality of life after infantile VGB exposure. Given our subjective impression that meaningful vision loss is seldom encountered among our VGB-treated patients with infantile spasms, we set out to systematically review the UCLA experience with VGB and VAVFL.

\section{Methods}




\section{Standard Protocol Approvals}

This use of human subjects and the analyses presented here were approved by the Institutional Review Board at UCLA. The requirement for written informed consent was waived.

\section{Data Ascertainment}

Patients with video-EEG confirmed infantile spasms evaluated at UCLA between February 2007 and February 2014 were retrospectively identified by searching a clinical EEG database that includes all patients who underwent video-EEG at our center. Based on review of serial neurologic and ophthalmologic reports, we ascertained whether each patient had evidence of clinically apparent vision loss of any cause, defined as vision loss noted on exam by neurologists or ophthalmologists at any follow-up visit. We considered vision loss to be potentially caused by VGB if the pattern of loss was both peripheral and bilateral. Among patients with VGB exposure, we documented relevant clinical factors and carefully tabulated the duration of therapy, peak dosage, and cumulative dosage. Medical record abstracters were not blinded to VGB exposure.

\section{$\underline{\text { Statistical Methods }}$}

Continuous summary data are presented as mean (standard deviation) or median (interquartile range), as appropriate, unless otherwise noted. Unpaired comparisons of proportions were accomplished using the Fisher Exact or Chi-Square tests, as appropriate. Unpaired comparisons of medians were accomplished using the Wilcoxon Rank Sum test.. Ninety-five percent confidence intervals $(95 \% \mathrm{Cl})$ for percentages were calculated using the modified Wald method.[26] Calculations were accomplished with STATA statistical software (StataCorp LP, Version 11, College Station, Texas, USA).

\section{Results}

\section{Patients}

Characteristics of the study population are summarized in Table 1. During the study period, 143 of 257 (56\%) patients with video-EEG confirmed infantile spasms received VGB. VGB-exposed children were slightly younger than VGB-naïve children at the time of infantile spasms onset $(p=0.003)$. Similarly, VGB-treated patients were younger at the time of data abstraction $(p=0.024)$, likely because the United State Food and Drug Administration approved VGB 18-months after the beginning of the study period. VGB treatment was not associated with sex or etiology, with the exception of Tuberous Sclerosis Complex (TSC). All 23 patients with TSC were treated with VGB $(p<0.001)$. Etiology of infantile spasms was known among 199 (77\%) and unknown among 58 (23\%) cases. Of those with unknown etiology, only 24 (9\%) were classically cryptogenic with normal development prior to spasms onset.

\section{Vigabatrin Exposure and Efficacy}

Of the 143 patients who received VGB, exact dosages, dates of therapy and dose changes were available for 104 (73\%), and are summarized in Table 2. The vast majority of patients with inadequate documentation of exposure received VGB prior to first UCLA evaluation. For these 104 patients, median 
age at treatment was $10.8(7.2-22.7)$ months and median duration of therapy was $8.6(3.7-16.2)$ months. From the start of vigabatrin to most recent clinical encounter, median follow-up time was 29.6 (14.8 - 48.8) months. Median peak dosage was $141.5(104.8-166.0) \mathrm{mg} / \mathrm{kg} /$ day and median weightedaverage dosage was 115.0 (88.4 - 144.0). Median cumulative dosage was 314.0 (140.8 - 645.7) grams, or $31.2(11.5-50.8)$ grams $/ \mathrm{kg}$ (i.e. total grams of VGB divided by weighted-average weight during the exposure period). Clinical resolution of spasms was noted in the medical record for 38 (36.5\%) patients, though documentation of extended video-EEG verifying complete absence of both spasms and hypsarrhythmia was present for only 22 (21.2\%). This discrepancy generally occurred because documentation of a follow-up EEG could not be ascertained. Of note, there were two patients for whom a clinically-reported response was contradicted by video-EEG demonstrating persistent albeit subtle spasms. These two patients were classified as non-responders.

VGB was the first treatment for infantile spasms in only 10 (9.6\%) patients. In many cases, spasms emerged in the context of other seizure types and other co-administered AEDs. Patients were exposed to a median of $3(2-4)$ therapies prior to starting VGB. An adequate trial of hormonal therapy before VGB treatment was documented in $42(40.4 \%)$ patients. The introduction of VGB was often quite delayed, with a median latency from spasms onset to VGB initiation of 4.4 (IQR $1.5-12.8$ ) months.

Patients with TSC were distinct with respect to VGB exposure and response, as summarized in Table 3. As might be expected, median duration and cumulative dosage of VGB was substantially higher among children with TSC (both comparisons, $p=0.001$ ). Conversely, children with TSC exhibited lower median peak dosage $(p=0.034)$ and lower median weighted-average dosage $(p=0.037)$. The latter observations may be attributed to early response at lower dosages or a lack of weight-based titration during longer courses (often in the setting of continued focal seizures). Indeed, reported response for treatment of infantile spasms was more frequent among those with TSC ( $56.3 \%$ versus $33.0 \%, p=0.045$ ).

$\underline{\text { Visual Field Loss }}$

Vision loss was identified among 45 (31\%) children with VGB exposure, including patients without detailed exposure data. The prevalence of vision loss was nearly identical among children without VGB exposure (37/114, 32\%). Importantly, there were no cases in which identified visual defects were plausibly linked to VGB. Vision loss was never characterized as bilateral and peripheral, and it was always attributed to other causes. Based on a lack of clinically apparent VAVFL observed in this series of 143 patients, we estimate the risk does not exceed 3.2\% (95\% Cl upper bound, modified Wald method). Alternative causes of visual field loss included cortical vision impairment in the setting of hypoxic ischemic encephalopathy, stroke, intracerebral hemorrhage, brain tumor, and surgical resection, as well as disorders of the retina (septo-optic dysplasia, retinal dystrophy, and Aicardi syndrome). Of note, children were still relatively young at most recent follow-up, with a median age of $4.1(2.2-6.7)$ years.

As expected, the exact methods employed by practitioners to interrogate visual fields varied greatly as a function of patient age and developmental status. Among the minority of patients with favorable developmental outcomes and excellent participation, practitioners routinely performed a thorough confrontational field exam with a variety of visual stimuli. However, among most children, patient age or 
developmental status impacted the assessment. In these cases, it was typical that practitioners carried out a "best possible" confrontational exam with the improvised use of a lighted object, toy, or other developmentally-appropriate visual stimulus capable of eliciting patients' attention.

Clinical evaluation by an ophthalmologist was documented for 91 (88\%) of the 104 patients with adequate exposure data. The remaining 13 patients were either (1) exempted from evaluation because of preexisting blindness or neurological devastation which precluded the need for visual assessment, or (2) received VGB prior to the 2009 FDA approval which mandated formal ophthalmologic evaluation. Although ophthalmologic assessment was frequently accomplished, formal perimetry assessment was almost never performed given the young age of patients.

\section{Electroretinography}

Although electroretinography (ERG) is arguably the best method to assess retinal function in a young or uncooperative patient, this procedure was seldom performed. ERG was documented among just 21 (20\%) patients, and actual ERG data were available for only 10 (10\%). At our center we typically limit ERG testing to those patients with at least 6 months of VGB exposure. No patient had documentation of baseline ERG prior to VGB initiation, and only three patients underwent serial ERG testing. All studies in this series were interpreted as normal or borderline normal except for one study in a patient with retinal dystrophy in which responses during cone-isolated and $30-\mathrm{Hz}$ flicker testing exhibited substantially reduced amplitude, increased latency, and marked asymmetry. In the remaining patients, we observed moderately low $30-\mathrm{Hz}$ flicker amplitudes with median peak-to-trough amplitude of $83.2 \mu \mathrm{V}$ (range, 40.8 - 127.7; normal range 94 -235), following a median VGB exposure of 17.2 (range 1.9 - 37.4) months. None of these patients had a pre-treatment ERG for comparison.

\section{Discussion}

This study supports the notion that relatively brief VGB exposure in infancy does not meaningfully increase the risk of clinically apparent vision loss-specifically, visual field defects of sufficient severity to be noted by parents, or discerned by neurologists and ophthalmologists during routine clinical encounters in childhood.

There are several notable limitations to our estimate of VAVFL risk. Our ability to ascertain VAVFL is limited by the retrospective design with unblinded clinician assessment, the reliance on documentation of vision loss in medical records, the rare implementation of serial ERG, and the lack of baseline ERG examinations. The vast majority of children in this cohort are presently too young to undergo a valid visual field assessment with kinetic perimetry. Furthermore, many patients in this series suffer neurodevelopmental impairment that precludes a meaningful clinical assessment of visual fields, even when performed by an experienced pediatric ophthalmologist. Lastly, nearly one-third of children exhibited other forms of vision loss. It is quite possible that mild-and even severe-VAVFL escaped recognition when simply overshadowed by profound visual field defects such as cortical blindness accompanying hypoxic ischemic encephalopathy. Consequently, we suspect that the prevalence of VAVFL is underestimated in this study. 
Two recent cohort studies[21,24] found that the risk of VAVFL is lower among children with brief exposure. More than half of the patients in our cohort were exposed to VGB for less than nine months, and the vast majority were exposed for less than two years. In comparison to prior studies evaluating VGB-treated infants, $[16,17,21,24]$ exposure in our cohort tended to be similar with respect to peak weight-based dosage but somewhat shorter with respect to duration of therapy. It is possible that short treatment duration contributed to the low rate of VAVFL in our patients. Similarly, there may be agespecific retinal and developmental adaptations that allow patients to compensate for VAVFL. As the patients in this series received VGB as infants, these potential adaptions might further complicate the identification of VAVFL by neuro-ophthalmologic examination.

To obtain vigabatrin in the United States, regulatory procedures require that parents/legal guardians provide written acknowledgement that "about 1 in 3 patients taking Sabril [vigabatrin] has vision damage."[27] This statement may be misleading given available data suggesting that VAVFL risk is lower in younger children who undergo a shorter duration of treatment. Our study further suggests that VGB confers little incremental risk of noticeable, life-limiting vision impairment. It is certainly not the case that $33 \%$ of children who have received VGB for treatment of infantile spasms suffer clinically obvious or otherwise debilitating vision loss recognized by families or healthcare providers. In light of our data, the requirement for patients with infantile spasms to undergo clinical ophthalmologic evaluations every three months-without a specific requirement for ERG testing - is not useful. If ERG is to be administered, it should be performed at baseline and periodically among patients embarking on courses of therapy exceeding six months.

Although we worry that VGB use might jeopardize our patients' ability to drive a car or perform other tasks that require robust peripheral vision as adults, we are far more concerned that unsuccessful treatment-and the underlying causes of infantile spasms - will yield intellectual disability and compromise all aspects of life, not just activities that require intact peripheral vision. Foremost, we suspect many patients and practitioners continue to forgo therapy with VGB with the belief that devastating vision loss is common. In counseling the parents of children with infantile spasms, an appropriate discussion of the risks, benefits, and alternatives to VGB should highlight continued uncertainty as to the exact risk and severity of VAVFL among infants, and clearly acknowledge the neurodevelopmental threat posed by unsuccessful treatment of infantile spasms. With brief (i.e., $<6-9$ months) exposure to VGB, the prevalence of ERG- and perimetry-defined VAVFL appears to be low, and the prevalence of clinically apparent VAVFL in childhood is very low. Available data, including the observations presented here, suggest that the greatest risk of VGB is not VAVFL; like all available therapies for infantile spasms, the real danger is that it simply might not work.

\section{Acknowledgements}

This investigator-initiated study was accomplished with an unrestricted grant from Lundbeck, LLC. The sponsor did not contribute to the study design, data collection, analysis, interpretation, drafting of the manuscript, or decision to submit the article for publication. We thank Dr. Steven Nusinowitz for his critical review of the manuscript. 


\section{Disclosures / Potential Conflict of Interests}

Dr. Sankar serves on scientific advisory boards for and has received honoraria and funding for travel from Acorda Therapeutics, Cyberonics, UCB Pharma, Sunovion, Upsher-Smith, and Lundbeck Pharma; receives royalties from the publication of Pediatric Neurology, 3rd ed. (Demos Publishing, 2008) and Epilepsy: Mechanisms, Models, and Translational Perspectives (CRC Press, 2011); serves on speakers' bureaus for and has received speaker honoraria from UCB, Supernus, Cyberonics, and Lundbeck. He has also received research support from the Bluebird Bio, Acorda Therapeutics, Insys Therapeutics, NIMH and NINDS.

Dr. J. Wu serves on the professional advisory board for the Tuberous Sclerosis Alliance; has received honoraria from and serves on the scientific advisory board and the speakers' bureau for Novartis Pharmaceuticals Inc. and Lundbeck; and has received research support from the Tuberous Sclerosis Alliance, Novartis Pharmaceuticals Inc., Today's and Tomorrow's Children Fund, Department of Defense/Congressionally Directed Medical Research Program, and the NIH (U01NS082320, P20NS080199, R01NS082649, and U54NS092090).

Dr. Hussain received an unrestricted grant from Lundbeck LLC to conduct this study, and has received research support from the Epilepsy Therapy Project, Milken Family Foundation, Hughes Family Foundation, the Elsie and Isaac Fogelman Endowment, Eisai inc., Insys Therapeutics, GW Pharmaceuticals, and the NIH (R34MH089299), and has received personal compensation for service on the scientific advisory boards of Questcor Pharmaceuticals and Upsher-Smith Laboratories, and as a consultant to Eisai inc.

Ms. Schwarz, Ms. Li, Mr. Zhou, Ms. Tsao. Mr. Zhou, Dr. Y. Wu have no financial disclosures to report.

\section{References}

[1] Shields WD. Infantile Spasms: Little Seizures, BIG Consequences. Epilepsy Currents 2006;6:63-9.

[2] Hrachovy RA, Frost JD, Kellaway P. Hypsarrhythmia: variations on the theme. Epilepsia 1984;25:317-25.

[3] O'Callaghan FJK, Lux AL, Darke K, Edwards SW, Hancock E, Johnson AL, et al. The effect of lead time to treatment and of age of onset on developmental outcome at 4 years in infantile spasms: evidence from the United Kingdom Infantile Spasms Study. Epilepsia 2011;52:1359-64.

[4] Hussain SA, Shinnar S, Kwong G, Lerner JT, Matsumoto JH, Wu JY, et al. Treatment of infantile spasms with very high dose prednisolone before high dose adrenocorticotropic hormone. Epilepsia 2014;55:103-7.

[5] Baram TZ, Mitchell WG, Tournay A, Snead OC, Hanson RA, Horton EJ. High-dose corticotropin (ACTH) versus prednisone for infantile spasms: a prospective, randomized, blinded study. Pediatrics 1996;97:375-9.

[6] Elterman RD, Shields WD, Bittman RM, Torri SA, Sagar SM, Collins SD. Vigabatrin for the treatment of infantile spasms: final report of a randomized trial. J Child Neurol 2010;25:1340-7.

[7] Appleton RE, Peters AC, Mumford JP, Shaw DE. Randomised, placebo-controlled study of vigabatrin as first-line treatment of infantile spasms. Epilepsia 1999;40:1627-33.

[8] Elterman RD, Shields WD, Mansfield KA, Nakagawa J, US Infantile Spasms Vigabatrin Study Group. Randomized trial of vigabatrin in patients with infantile spasms. Neurology 2001;57:1416-21. 
[9] Eke T, Talbot JF, Lawden MC. Severe persistent visual field constriction associated with vigabatrin. BMJ 1997;314:180-1.

[10] Vanhatalo S, Nousiainen I, Eriksson K, Rantala H, Vainionpää L, Mustonen K, et al. Visual field constriction in 91 Finnish children treated with vigabatrin. Epilepsia 2002;43:748-56.

[11] Pearl PL, Vezina LG, Saneto RP, McCarter R, Molloy-Wells E, Heffron A, et al. Cerebral MRI abnormalities associated with vigabatrin therapy. Epilepsia 2009;50:184-94.

[12] Wheless JW, Carmant L, Bebin M, Conry JA, Chiron C, Elterman RD, et al. Magnetic resonance imaging abnormalities associated with vigabatrin in patients with epilepsy. Epilepsia 2009;50:195205.

[13] Fong CY, Osborne JP, Edwards SW, Hemingway C, Hancock E, Johnson AL, et al. An investigation into the relationship between vigabatrin, movement disorders, and brain magnetic resonance imaging abnormalities in children with infantile spasms. Developmental Medicine \& Child Neurology 2013;55:862-7.

[14] Hernández Vega Y, Kaliakatsos M, U-King-Im J, Lascelles K, Lim M. Reversible vigabatrin-induced life-threatening encephalopathy. JAMA Neurol 2014;71:108-9.

[15] Maguire MJ, Hemming K, Wild JM, Hutton JL, Marson AG. Prevalence of visual field loss following exposure to vigabatrin therapy: a systematic review. Epilepsia 2010;51:2423-31.

[16] Gaily E, Jonsson H, Lappi M. Visual fields at school-age in children treated with vigabatrin in infancy. Epilepsia 2009;50:206-16.

[17] Wohlrab G, Leiba H, Kästle R, Ramelli G, Schmitt-Mechelke T, Schmitt B, et al. Vigabatrin therapy in infantile spasms: Solving one problem and inducing another? Epilepsia 2009;50:2006-8.

[18] Versino M, Veggiotti P. Reversibility of vigabatrin-induced visual-field defect. The Lancet 1999;354:486.

[19] Giordano L, Valseriati D, Vignoli A, Morescalchi F, Gandolfo E. Another case of reversibility of visual-field defect induced by vigabatrin monotherapy: is young age a favorable factor? Neurol Sci 2000;21:185-6.

[20] Riikonen R. Is the risk of vigabatrin-attributed visual field loss lower in infancy than in later life? Epilepsia 2009;50:2005-6.

[21] Riikonen R, Rener-Primec Z, Carmant L, Dorofeeva M, Hollody K, Szabo I, et al. Does vigabatrin treatment for infantile spasms cause visual field defects? An international multicentre study. Dev Med Child Neurol 2015;57:60-7.

[22] Good WV, Jan JE, DeSa L, Barkovich AJ, Groenveld M, Hoyt CR eig S. Cortical visual impairment in children. Survey of Ophthalmology 1994;38:351-64.

[23] Sergott RC. Recommendations for visual evaluations of patients treated with vigabatrin. Curr Opin Ophthalmol 2010;21:442-6.

[24] Westall CA, Wright T, Cortese F, Kumarappah A, Snead OC, Buncic JR. Vigabatrin retinal toxicity in children with infantile spasms: An observational cohort study. Neurology 2014;83:2262-8.

[25] Moskowitz A, Hansen RM, Eklund SE, Fulton AB. Electroretinographic (ERG) responses in pediatric patients using vigabatrin. Doc Ophthalmol 2012;124:197-209.

[26] Agresti A, Coull BA. Approximate is Better than "Exact" for Interval Estimation of Binomial Proportions. The American Statistician 1998;52:119-26.

[27] Patient/Parent/Legal Guardian - Physician Agreement n.d. http://sabril.net/hcp/rems_forms/forms/patient_physician_agreement_form.aspx (accessed July 27, 2015). 


\begin{tabular}{|c|c|c|c|}
\hline & $\begin{array}{c}\text { VBG Exposed } \\
(n=143)\end{array}$ & $\begin{array}{l}\text { VGB Naïve } \\
(n=114)\end{array}$ & $\mathrm{p}$ value \\
\hline \multicolumn{4}{|l|}{ Demographics } \\
\hline Age at infantile spasms onset, $\mathrm{mo}^{\mathrm{a}}$ & $6.0(3.3-18.0)$ & $6.8(4.0-18.0)$ & $0.003^{b}$ \\
\hline Age at the time of data abstraction, $\mathrm{y}^{\mathrm{a}}$ & $7.5(5.0-9.3)$ & $8.3(6.7-10.5)$ & $0.024^{b}$ \\
\hline Female sex, $\mathrm{n}(\%)$ & $67(47 \%)$ & $46(40 \%)$ & $N S^{c}$ \\
\hline \multicolumn{4}{|l|}{ Etiology } \\
\hline Known cause, $(\%)$ & $108(76 \%)$ & 91 (79\%) & NS \\
\hline Tuberous Sclerosis Complex, $\mathrm{n}(\%)$ & $23(16 \%)$ & $0(0 \%)$ & $<0.001^{d}$ \\
\hline Unknown cause, $\mathrm{n}(\%)$ & $35(24 \%)$ & $23(20 \%)$ & NS \\
\hline "Cryptogenic" , n (\%) & $11(8 \%)$ & $13(11 \%)$ & NS \\
\hline
\end{tabular}

${ }^{a}$ Median (interquartile range)

${ }^{b}$ Comparison by Wilcoxon Rank Sum test.

${ }^{\mathrm{c}}$ Not significant

${ }^{\text {d}}$ Comparison by Fisher Exact test.

"“Cryptogenic" refers to patients with unknown etiology and normal development prior to infantile spasms onset. 


\begin{tabular}{|c|c|}
\hline \multicolumn{2}{|l|}{ VGB exposure $\left(n=104^{a}\right)$} \\
\hline Duration of treatment, months ${ }^{\mathrm{b}}$ & $8.6(3.7-16.2)$ \\
\hline Peak dosage, $\mathrm{mg} / \mathrm{kg} / \mathrm{day}^{\mathrm{b}}$ & $141.5(104.8-166.0)$ \\
\hline Weighted-average dosage, $\mathrm{mg} / \mathrm{kg} / \mathrm{day}^{\mathrm{b}}$ & $115.0(88.4-144.0)$ \\
\hline Cumulative dose, grams $^{\mathrm{b}}$ & $314.0(140.8-645.7)$ \\
\hline \multicolumn{2}{|l|}{ Clinically apparent vision loss ( $n=143$ ) } \\
\hline Vision loss of any cause, $\mathrm{n}(\%)$ & $45(31)$ \\
\hline Vision loss attributed to VGB, $\mathrm{n}(\%)$ & $0(0)$ \\
\hline
\end{tabular}

${ }^{a}$ Includes only patients with detailed exposure data available

${ }^{b}$ Median (interquartile range) 


\begin{tabular}{|c|c|c|c|}
\hline & $\begin{array}{c}\text { TSC } \\
(n=16)\end{array}$ & $\begin{array}{l}\text { Non-TSC } \\
(n=88)\end{array}$ & p-value \\
\hline \multicolumn{4}{|l|}{ Vigabatrin Exposure } \\
\hline Duration of treatment, months ${ }^{a}$ & $15.2(11.8-39.5)$ & $7.9(3.2-13.7)$ & $0.001^{b}$ \\
\hline Peak dosage, $\mathrm{mg} / \mathrm{kg} / \mathrm{day}^{\mathrm{a}}$ & $124.6(97.5-141.8)$ & $147.1(105.6-169.1)$ & $0.034^{b}$ \\
\hline Weighted-average dosage, $\mathrm{mg} / \mathrm{kg} / \mathrm{day}^{\mathrm{a}}$ & $99.6(84.5-112.0)$ & $118.3(89.4-137.1)$ & $0.037^{b}$ \\
\hline Cumulative dose, grams ${ }^{a}$ & $731.0(452.2-1627.7)$ & $271.8(90.2-553.2)$ & $0.001^{b}$ \\
\hline \multicolumn{4}{|l|}{ Efficacy } \\
\hline Response, n (\%) & $9(56.3 \%)$ & 29 (33.0\%) & $0.045^{c}$ \\
\hline
\end{tabular}

${ }^{a}$ Median (interquartile range)

${ }^{\mathrm{b}}$ Comparison by Wilcoxon Rank-Sum test.

${ }^{\mathrm{c} C o m p a r i s o n}$ by Chi-Square test. 